\title{
Genetic Variation and Response to Selection for Early Season Fruit Production in California Strawberry Seedling (Fragaria $\times$ ananassa Duch.) Populations
}

\author{
Douglas V. Shaw ${ }^{1}$ and Kirk D. Larson \\ Department of Pomology, One Shields Avenue, University of California, Davis, CA 95616
}

\begin{abstract}
ADDITIONAL INDEX WORDS. heritability, genetic correlation, genotype $\times$ environment interaction
Aвstract. The genetic opportunity for selection of early fruiting strawberry cultivars was evaluated using seedling populations from the Univ. of California (UC) breeding program in three years. Narrow-sense heritabilities for early season yield and for the proportion of an individual's total yield expressed early were moderate $\left(h^{2}=0.24-0.53\right)$ and broad-sense heritabilities were slightly larger $\left(\mathrm{H}^{2}=0.31-0.70\right)$, suggesting the presence of some nonadditive genetic variance for these traits. These two traits were genetically correlated with each other $\left(r_{g}=0.78-0.98\right)$, but only early yield was consistently genetically correlated with seasonal yield $\left(r_{g}=0.52-0.82\right)$. Selection was performed for each trait using an index on full-sib family means and individual phenotypic values in two of the three years, and predicted response was compared with that obtained using vegetatively propagated runner plants from selected genotypes in the subsequent fruiting season. Statistically significant $(P<0.05)$ selection response was obtained in one of two years for each trait, and combined analysis demonstrated highly significant $(P<0.01)$ response for both traits. However, realized response over all traits and years was just $27.3 \%$ of that predicted based on the estimated heritabilities and applied selection intensities. These results suggest that selection for early yield should be based at least in part on runner plant evaluations rather than exclusively on seedling performance.
\end{abstract}

The production season for commercial strawberry has been extended dramatically in Mediterranean and subtropical environments during the past several decades (Bertelsen, 1995). Seasonal extension has been bi-directional, with earlier production obtained in warm-winter environments and extended fruiting into summer and fall for cool-summer coastal locations. Extending the production pattern into the winter months has been achieved through manipulation of cultural and environmental factors, and through the development of cultivars that are predisposed to early fruiting in these environments (Bringhurst, 1981; Chandler, 1991; Voth and Bringhurst, 1990).

The contributions of cultural manipulation to early season fruit production in strawberry have been well documented. Production pattern in commercial strawberry depends critically on a number of plant growth and environmental factors that affect flower induction and expression (Durner et al., 1984; Larson, 1994; Shaw, 1992; Voth and Bringhurst, 1970; Walsh et al., 1997). In locations with warm winters, the application of knowledge about these basic controlling factors has led to annual planting systems, the development of specialized nurseries for runner production, and a variety of recommendations for postnursery plant treatment (Durner et al., 1986; Voth and Bringhurst, 1990).

Despite the commercial importance of early season productivity, very little has been published regarding the genetics of early season fruiting in strawberry. Early season production has been a target of several breeding programs, and commercial production of fruit has increased during the winter months (Bringhurst, 1981;

Received for publication 13 May 2004. Accepted for publication 19 June 2004.

'To whom correspondence should be addressed; e-mail: dvshaw@ucdavis.edu
Chandler, 1991; Hancock and Scott, 1989). Barritt et al. (1982) demonstrated substantial genetic variation for early flowering in northern latitudes, but early flowering in their study was related to genes conferring day-neutrality, whereas most early season breeding programs depend exclusively on short-day cultivars. The extent to which the observed historical increases in winter fruit production are due to genetic improvement, changes in the cultural environment, or an interaction of the two factors is not clear (Voth and Bringhurst, 1990), and thus the opportunities for further development of early season fruiting potential are difficult to predict.

The objective of our study was to quantify the opportunity for further development of cultivars with high production capacity during the late fall and winter months in semi-arid, subtropical environments. The initial step in this determination was the estimation of relevant genetic and environmental variance parameters in seedling populations, and this step was followed by an empirical determination of realized selection response. One confounding factor in breeding early-fruiting strawberry cultivars is that selection early in the generational cycle for many programs is based on performance of seedlings, whereas commercial fields are uniformly established using vegetatively propagated runner plants. Clear differences have been detected between seedlings and runner plants for the expression of productivity traits (Pringle and Shaw, 1997; Shaw, 1989a). Early season fruit production is especially affected by environmental manipulation of the strawberry plant (Voth and Bringhurst, 1990), so might be expected to differ in genetic expression between seedlings and runner plants as well. Thus a second objective of this research was to evaluate the response realized in the eventual commercial propagule type, runner plants, when selection is performed on seedling phenotypes. 


\section{Materials and Methods}

Seedlings from each of 74 bi-parental crosses among 30 parent genotypes were evaluated at the Univ. of California (UC) South Coast Research and Extension Center in Irvine, Calif. (lat. $33^{\prime} 41^{\prime \prime} \mathrm{N}$, long. $\left.117^{\prime} 43^{\prime \prime} \mathrm{W}\right)$, over three trial years: 1999, 2000 , and 2002. In each year the trial population included 24 or 25 crosses among 10 parents, arranged in a $5 \times 5$ factorial breeding design (Combstock and Robinson, 1948); one cross was missing in the 1999 set. These populations were a representative subset of the seedlings used for development of early-fruiting short-day cultivars by the UC strawberry improvement program. The Irvine environment is characteristic of those used for commercial production in the south coast region of California with a mean January and July temperatures of 13 and $23^{\circ} \mathrm{C}$, respectively.

Thirty seedlings from each cross were established in mid-September preceding the fruit evaluation year using a randomized complete-block design with three blocks and a single plot of 10 seedlings per block. Fruit was harvested and its weight recorded weekly from individual seedlings for 25-28 weeks. Further analyses were performed using the yield obtained during the first 8 weeks of harvest (early yield) and the proportion of the seasonal yield represented by the fruit harvested during this interval (early yield fraction). Yearly climatic variation caused small differences in the timing of the first harvest and the length of the fruiting season, but early yield was calculated as that amount produced prior to $1-8$ Mar. in all three years. Commercial strawberry growers in this region use yield to 1 Mar. as an index of early fruit production (and relatively high market prices) in evaluating both cultivars and cultural systems (Jiang and Goodhue, 2003).

Analyses of variance (ANOVAs) were conducted for each trial separately using SAS Procedure GLM with a factorial experimental design (SAS Institute, 1990). Males, females, and male $\times$ female interaction were treated as random effects, and Blocks were treated as a fixed effect. Model variance components were estimated using SAS Procedure VARCOMP and components of covariance were derived from the MANOVA option of SAS procedure GLM. Causal components of variance and covariance were estimated from linear functions of expected mean squares and cross products. Narrow sense heritabilities $\left(h^{2}\right)$, broad sense heritabilities $\left(\mathrm{H}^{2}\right)$, and genetic correlations were estimated as (Becker, 1984):

$h^{2}=\frac{2\left(\sigma_{m}^{2}+\sigma_{f}^{2}\right)}{\sigma_{m}^{2}+\sigma_{f}^{2}+\sigma_{m f}^{2}+\sigma_{w}^{2}}$

$\mathrm{H}^{2}=\frac{2\left(\sigma_{\mathrm{m}}^{2}+\sigma_{\mathrm{f}}^{2}\right)+4 \sigma_{\mathrm{mf}}^{2}}{\sigma_{\mathrm{m}}^{2}+\sigma_{\mathrm{f}}^{2}+\sigma_{\mathrm{mf}}^{2}+\sigma_{\mathrm{w}}^{2}}$

$r_{g}=\frac{2\left(\sigma_{x y(m)}+\sigma_{x y(f)}\right)}{\left[2\left(\sigma_{x m}^{2}+\sigma_{x f}^{2}\right) * 2\left(\sigma_{y m}^{2}+\sigma_{y f}^{2}\right)\right]^{1 / 2}}$

In Eqs. [1] and [2], $\sigma^{2}{ }_{\mathrm{m}}, \sigma_{\mathrm{f}}^{2}, \sigma_{\mathrm{mf}}^{2}$, and $\sigma^{2}{ }_{\mathrm{w}}$ are variances due to male parents, female parents, male $\times$ female interaction and an error variance that includes within-family genetic and environmental sources (Hallauer and Miranda, 1981). In Eq. [3], $\sigma_{x y(m)}$ and $\sigma_{x y(f)}$ are the components of covariance for traits $x$ and $y$ due to male and female parents, and $\sigma_{x(\mathrm{~m})}^{2}, \sigma^{2}{ }_{x(\mathrm{f})}, \sigma^{2}{ }_{x(\mathrm{~m})}$, and $\sigma^{2}{ }_{x(\mathrm{f})}$ are the trait specific variances due to male and female parents as applied in Eqs. [1] and [2].
After evaluations were complete in 1999 and 2002, the information collected was used to make selections for further resolution of genetic potential. Ten to 14 selected genotypes were retained for each of the two early-production variables in each of these two years using an index on full-sib family means and individual phenotypic values (Van Vleck, 1983). Individuals in the selected groups were limited to a maximum of three per bi-parental cross, and this restricted index procedure resulted in standardized selection intensities of $i=2.17-2.50$. A control group of 12 randomly chosen genotypes was also retained from each trial. Selection response was predicted for each character and trial year combination using the genetic expectations calculated from ANOVA results in each year and formulas from Van Vleck.

Runner plants from each selected and control genotype were transplanted into fruiting evaluation trials on 15-16 Oct. of the seedling evaluation year (1999 and 2002), with each genotype represented by two plots of ten runner plants. Early yield and early yield fraction were obtained for runner plant trials as described above for seedlings. Selected and control group means were compared to evaluate the reliability of heritability estimates in predicting response in runner propagation systems from selection based on seedling phenotypes. The statistical significance of selection response for each variable was evaluated using Student's $t$ tests, and significance results for each variable were combined over the two trial years using Fisher's (1932) chi-square statistic:

$$
-2 \Sigma \log \mathrm{p}_{\mathrm{i}}=-2 \log \Pi \mathrm{p}_{\mathrm{i}}
$$

In Eq. [4], the $\mathrm{p}_{\mathrm{i}}$ are the probabilities of finding a larger value for the treated group than for the control group in each of the $\mathrm{k}$ studies, given that there is no real difference between treated and control sets; the individual $\mathrm{p}_{\mathrm{i}}$ are $P$ values obtained from a one-tailed probability test. This statistic has a chi-square distribution with $2 \mathrm{k}$ degrees of freedom under the null hypothesis of no differences between selected and control groups.

\section{Results and Discussion}

Seasonal yield for the seedling populations differed substantially over the three trial years, possibly due to annual differences in climate (Table 1). Seedling performance at this location depends on a number of climatic factors, including accumulated chilling hours and late-spring temperature (Larson, 1994), which can differ substantially among years. Despite substantial differences in seasonal yield, the early yield fraction was nearly identical for the three trials, suggesting substantial stability of expression for early production characteristics regardless of annual environmental fluctuations. The seedlings evaluated in each year derive from different sets of bi-parental crosses, so it is possible that the

Table 1. Means and standard deviations (in parentheses) for yield accumulated to early March (early yield), the proportion of yield accumulated to early March (early yield fraction), and the seasonal yield for strawberry seedling populations evaluated in three trial years.

\begin{tabular}{lcccc}
\hline $\begin{array}{l}\text { Trial } \\
\text { year }\end{array}$ & $\mathrm{N}$ & $\begin{array}{c}\text { Early } \\
\text { season yield } \\
(\mathrm{g} / \text { plant })\end{array}$ & $\begin{array}{c}\text { Early } \\
\text { yield fraction } \\
(\%)\end{array}$ & $\begin{array}{c}\text { Seasonal } \\
\text { yield } \\
(\mathrm{g} / \mathrm{plant})\end{array}$ \\
\hline 1999 & 714 & $238(155)$ & $23.6(14.1)$ & $1139(385)$ \\
2000 & 748 & $153(116)$ & $20.5(14.6)$ & $761(286)$ \\
2002 & 738 & $303(198)$ & $22.7(13.7)$ & $1324(424)$ \\
\hline
\end{tabular}


observed differences trace in part to genetic variation among the parents used in each set of crosses as well.

Variances due to male and female parents were statistically significant $(P<0.05)$ or highly significant $(P<0.01)$ for all but two cases, and at least one of these sources produced significant variances for each trait in each seedling population (Table 2). Parent genotypes were assigned to male and female subsets at random with respect to the production traits evaluated, so the variation over years here is most likely due to sampling alone. Narrow-sense heritabilites were moderate $\left(h^{2}=0.24\right.$ to 0.53$)$ for all traits except seasonal yield for the 2002 seedling population (Table 2), suggesting the presence of substantial additive genetic variation for both seasonal and early-season yield traits. Part-records analysis of strawberry yield in central California (Shaw, 1989b) demonstrated late-season decline in heritabilities for yield, consistent with the observation here that seasonal heritabilities were lower than those for early-season production traits. The difference in heritability for early and seasonal yield was especially large for the 2002 seedling population: the heritability for early season yield $\left(\mathrm{h}^{2}=0.53\right)$ was similar to those estimated in other years, but the heritability for seasonal yield $\left(h^{2}=0.10\right)$ was substantially smaller, suggesting the presence of large nongenetic factors in the phenotypic differences expressed late in the season.

Significant or highly significant male $\times$ female interaction variances were detected for all traits except the early yield fraction in the 2000 seedling population. Broad-sense heritabilities were moderate to large $\left(\mathrm{H}^{2}=0.22\right.$ to 0.73$)$, and were $20 \%$ to $120 \%$ larger than their complementary narrow-sense heritabilities for all traits (Table 2). The large relative size of broad-sense to narrow-sense heritability suggests the presence of considerable nonadditive genetic variation for traits that describe early yield. This observation suggests that a large fraction of the variation for early productivity, that due to nonadditivity, will not be cumulative over breeding cycles and can be captured only using vegetative propagation. However, a similar or larger fraction of the genetic variance present in this population is attributable to the additive effects of the loci that condition genetic variance, and this fraction will be cumulative over cycles of recurrent breeding and selection. Selection indexes that weight cross means heavily frequently improve resolution of the additive component of the genetic variance, and could thus improve the efficiency of obtaining cumulative genetic response for early yield, provided the correspondence for this character is large between seedlings and runner plants.

The genetic correlations for early yield and early yield fraction were $r_{g}=0.77-0.98$ for the three seedling populations, indicating that variation for the two traits is conditioned largely by the same sets of genes (Table 3). A similar pattern was observed between early yield and seasonal yield $\left(r_{g}=0.54-0.82\right)$, suggesting that selection for high early-season yield is compatible, perhaps even reinforcing, to selection for seasonal yield. Conversely, results for genetic correlations between early yield fraction and seasonal yield were heterogeneous over seedling populations (Table 3 ), being slightly negative for populations evaluated in 1999 and 2000, and significantly positive in 2002. This observation is compatible with the observation of low heritability for seasonal yield in the 2002 population, an observation that indicated the absence of genetic variation for late season yield in this trial. At worst, these observations suggest minor obstacles to the simultaneous improvement of early yield fraction and seasonal yield.

Evaluation of runner plant populations from genotypes retained from the 1999 and 2002 seedling populations revealed consistent but not uniformly significant selection response for early fruit production characters (Table 4). Selected population means were $18 \%$ to $41 \%$ larger than their respective control population means for early yield and early yield fraction in both trial years. Averaged over both runner plant trials, early yield was improved by $19.5 \%$ and early yield fraction by $25.1 \%$ relative to their respective control sets by the rather strong selection applied in this experiment. Individual comparisons detected significant or highly significant differences between selected and control groups for early yield in the 2000 trial, and early yield fraction for the 2003 trial. Combined analysis demonstrated highly significant selection response to both early production traits, with $\chi^{2}=16.5(P<0.01)$ for early yield and $\chi_{4}^{2}=14.7(P<0.01)$ for early yield fraction.

Despite the substantial realized response detected above, responses for all traits and years were just $16 \%$ to $43 \%$ of those predicted using the estimated heritabilities and the applied selection intensities (Table 4). Several explanations for this discrepancy are possible. Previous trials (Shaw, 1989c) detected large nonadditive

Table 2. Results for analysis of variance for yield accumulated to early March (early yield), the proportion of yield accumulated to early March (early yield fraction), and the seasonal yield for strawberry seedling populations evaluated in three trial years.

\begin{tabular}{|c|c|c|c|c|c|c|c|c|c|c|}
\hline \multirow[b]{3}{*}{ Source } & \multirow[b]{3}{*}{$\mathrm{df}^{\mathrm{z}}$} & \multicolumn{9}{|c|}{ Seedling trial year } \\
\hline & & \multicolumn{3}{|c|}{1999} & \multicolumn{3}{|c|}{2000} & \multicolumn{3}{|c|}{2002} \\
\hline & & $\begin{array}{l}\text { Early } \\
\text { yieldy }\end{array}$ & $\begin{array}{c}\text { Early } \\
\text { yield } \\
\text { fraction }\end{array}$ & $\begin{array}{c}\text { Seasonal } \\
\text { yieldy }\end{array}$ & $\begin{array}{l}\text { Early } \\
\text { yield }\end{array}$ & $\begin{array}{c}\text { Early } \\
\text { yield } \\
\text { fraction }\end{array}$ & $\begin{array}{c}\text { Seasonal } \\
\text { yieldy }\end{array}$ & $\begin{array}{l}\text { Early } \\
\text { yieldy }\end{array}$ & $\begin{array}{c}\text { Early } \\
\text { yield } \\
\text { fraction }\end{array}$ & $\begin{array}{c}\text { Seasonal } \\
\text { yieldy }\end{array}$ \\
\hline Block & 2 & $162.2^{* *}$ & $830.1^{\text {*** }}$ & $498.6^{*}$ & 18.0 & 175.8 & 43.9 & 33.9 & 145.1 & 261.2 \\
\hline Male (M) & 4 & $303.6^{*}$ & $4796.4^{* *}$ & 1222.6 & $22.4^{* * *}$ & $1679.0^{* *}$ & $2451.0^{* *}$ & $1057.6^{* *}$ & $4666.8^{* *}$ & 702.8 \\
\hline Female (F) & 4 & $426.2^{* *}$ & 795.8 & $4338.3^{* *}$ & $15.9^{* *}$ & $2939.3^{* *}$ & $70.9^{* *}$ & $697.5^{* *}$ & $3262.1^{* *}$ & $1259.2^{*}$ \\
\hline $\mathrm{M} \times \mathrm{F}$ & 15 & $75.5^{* *}$ & $726.2^{* *}$ & $527.2^{* *}$ & $2.2^{*}$ & 280.2 & $10.6^{*}$ & $61.9^{* *}$ & $339.7^{\text {** }}$ & $334.0^{*}$ \\
\hline Error & 688 & 19.5 & 145.2 & 110.1 & 1.1 & 189.2 & 6.4 & 29.4 & 140.8 & 167.4 \\
\hline \multirow[t]{2}{*}{$h^{2}$} & & $0.34^{x}$ & 0.32 & 0.43 & 0.32 & 0.24 & 0.45 & 0.53 & 0.50 & 0.10 \\
\hline & & $( \pm 0.23)$ & $( \pm 0.24)$ & $( \pm 0.29)$ & $( \pm 0.21)$ & $( \pm 0.16)$ & $( \pm 0.29)$ & $( \pm 0.33)$ & $( \pm 0.32)$ & $( \pm 0.09)$ \\
\hline \multirow[t]{2}{*}{$\mathrm{H}^{2}$} & & 0.62 & 0.70 & 0.77 & 0.43 & 0.31 & 0.53 & 0.64 & 0.64 & 0.22 \\
\hline & & $( \pm 0.36)$ & $( \pm 0.40)$ & $( \pm 0.44)$ & $( \pm 0.29)$ & $( \pm 0.22)$ & $( \pm 0.34)$ & $( \pm 0.40)$ & $( \pm 0.39)$ & $( \pm 0.17)$ \\
\hline
\end{tabular}

${ }^{2}$ Degrees of freedom for $\mathrm{M} \times \mathrm{F}$ interaction were 16 and 16, and error degrees of freedom were 721 and 711 in 2000 and 2001 , respectively.

yean squares are presented in thousands for simplification of the table.

$\times$ Heritabilities presented \pm SE estimated from Hallaeuer and Miranda, (1981).

*,**Significance at the 0.05 and 0.01 probability levels, respectively. 
Table 3. Genetic correlations for yield accumulated to early March (early yield), the proportion of yield accumulated to early March (early yield fraction), and the seasonal yield for strawberry seedling populations evaluated in three trial years.

\begin{tabular}{|c|c|c|c|}
\hline \multirow[b]{2}{*}{$\begin{array}{l}\text { Trial } \\
\text { year }\end{array}$} & \multirow[b]{2}{*}{ Trait } & \multicolumn{2}{|c|}{ Trait } \\
\hline & & $\begin{array}{c}\text { Early yield } \\
\text { fraction }\end{array}$ & $\begin{array}{c}\text { Seasonal } \\
\text { yield }\end{array}$ \\
\hline \multirow[t]{2}{*}{1999} & Early season yield & $0.77^{* *}$ & 0.52 \\
\hline & Early yield fraction & --- & -0.12 \\
\hline \multirow[t]{2}{*}{2000} & Early season yield & $0.78^{* *}$ & 0.54 \\
\hline & Early yield fraction & --- & -0.13 \\
\hline \multirow[t]{2}{*}{2002} & Early season yield & $0.98^{* *}$ & $0.82^{* *}$ \\
\hline & Early yield fraction & --- & $0.71^{*}$ \\
\hline
\end{tabular}

*,**Significance at the 0.05 and 0.01 probability levels, respectively.

Table 4. Trait means $( \pm \mathrm{SE})$ for selected and control groups, predicted and realized selection response, for yield accumulated to early March (early yield) and the proportion of yield accumulated to early March (early yield fraction) tested using runner plants in two trial years.

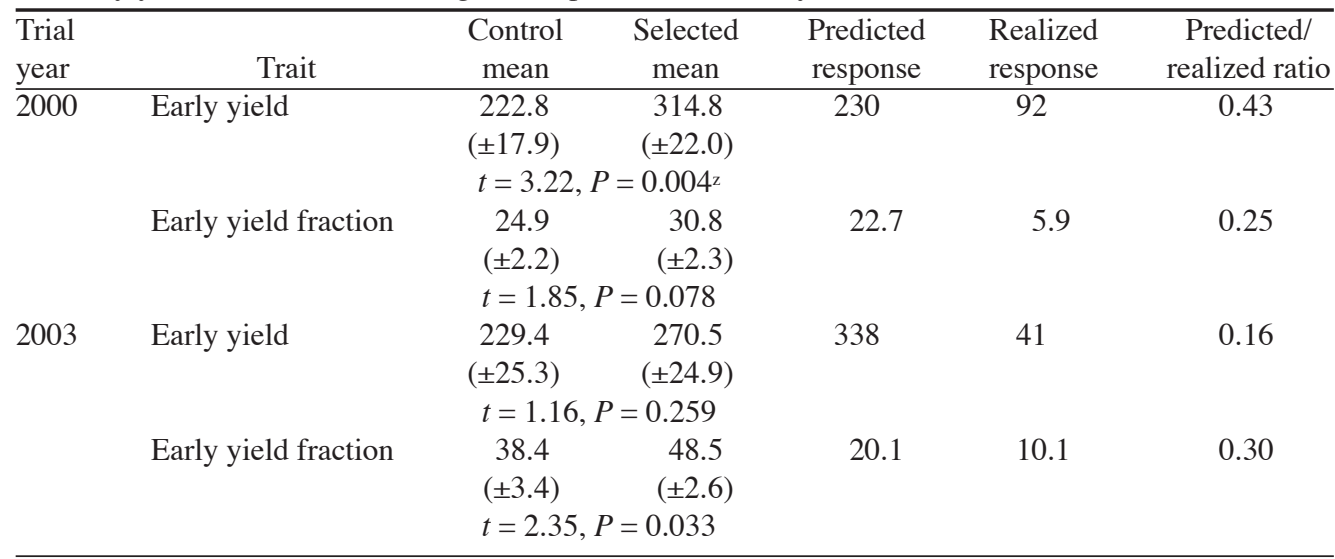

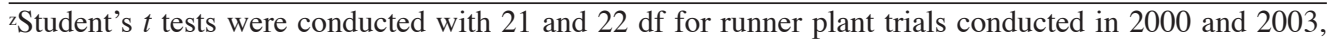
respectively.

components of variance for fruit yield in single-location trials, but these were later demonstrated to be genetic $\times$ location interaction variances. The nonadditive genetic variance demonstrated here could also be biased due to single year trials and may be responsible in part for the discrepancy in predicted and realized selection response. Other experiments suggest that genetic $\times$ propagule-type or genetic $\times$ propagule-treatment interaction is a likely explanation. If this discrepancy traces to inconsistency of genetic expression between seedling and runner plant propagation systems (Pringle and Shaw, 1997; Shaw, 1989a), care should be taken to base parent selection for early yield and early yield fraction primarily on genotypic performance in runner plant trials. Information about early season productivity for primary selection populations would be substantially more costly and time consuming to obtain using runner plants rather than seedlings. However, parent selection in most strawberry breeding programs is not usually performed until after initial seedling selections are tested using small plots of runner plants, thus such information should be available at minimal extra cost. A two-stage selection strategy, using an index on seedlings and runners, might be optimal. Regardless, selection response predicted using seedling results alone should be treated as best-case estimates.

Other selection strategies might also be employed to improve early season productivity in strawberry. For example, the procedures employed here ignore opportunities for selecting genotypes specifically adapted to earlier plantation establishment, which in itself results in earlier production. This approach thus assumes a consistent production environment, and does not incorporate potential gain from adaptation to modified cultural practices that in themselves may promote early production. Together, direct selection for inherent early season productivity and improvement of adaptation to cultural practices that promote early yield offer continuing opportunity for increasing early season fruit productivity in strawberry.

\section{Literature Cited}

Barritt, B.H., R.S. Bringhurst, and V. Voth. 1982. Inheritance of early flowering in relation to breeding day-neutral strawberries. J. Amer. Soc. Hort. Sci. 107:733-736.

Becker, W.A. 1984. Manual of quantitative genetics. Academic Enterprises, Pullman, Wash.

Bertelsen, D. 1995. The US Strawberry Industry: USDA-ERS Stat. Bul. No. 914.

Bringhurst, R.S. 1981. Strawberry production trends in the western USA, p. 13-21. In: N.F. Childers (ed.). The strawberry cultivars to marketing. Hort. Publ., Gainesville, Fla.

Chandler, Craig K. 1991. Chapter 8: NorthAmerican Strawberry Cultivars, p. 60-65. In: A. Dale and J.J. Luby (eds.). The strawberry into the 21st century. Timber Press, Portland, Ore.

Comstock, R.E. and H.F. Robinson. 1948. The components of genetic variation in populations of bi-parental progenies and their use in estimating the average degree of dominance. Biometrics 4:254-266.

Durner, E.F., J.A. Barden, D.G. Himelrick, and E.B. Poling. 1984. Pho- 
toperiod and temperature effects on flower and runner development in day-neutral, June-bearing, and everbearing strawberries. J. Amer. Soc. Hort. Sci. 109:396-400.

Durner, E.F., E.B. Poling, and E.A. Albregts. 1986. Early season yield responses to selected strawberry cultivars to photoperiod and chilling in a Florida winter production system. J. Amer. Soc. Hort. Sci. 111:53-56.

Fisher, R.A. 1932. Statistical methods for research workers. 4th ed. Oliver and Boyd, London.

Hallauer, A.R. and J.B. Miranda. 1981. Quantitative genetics and maize breeding. Iowa State Univ. Press, Ames.

Hancock, J.F. and D.H. Scott. 1989. Strawberry cultivars and worldwide patterns of strawberry production. Fruit Var. J. 42(3):102-108.

Jiang, J.Z. and R.E. Goodhue. 2003. Prices, volumes and promotions in the fresh strawberry market. Agr. Res. Econ. Update, Giannini Foundation of Agr. Econ., Univ. of Calif. 6(3):9-11.

Larson, K.D. 1994. Strawberry, p. 271-297. In: B. Schaffer and P.C. Andersen (eds.). Hdbk. of Environmental Physiology of Fruit Crops. Vol. I. Temperate fruits. CRC Press, Boca Raton, Fla.

Pringle, G.J. and D.V. Shaw. 1997. Predicted and realized response of strawberry production traits to selection in differing environments and propagation systems. J. Amer. Soc. Hort. Sci. 123:61-66.

SAS Institute. 1990. SAS/STAT user's guide, release 6.04. SAS Inst., Cary, N.C.
Shaw, D.V. 1989a. Variation among heritability estimates for strawberries obtained by offspring-parent regression with relatives raised in separate environments. Euphytica 44:157-162.

Shaw, D.V. 1989b. Genetic parameters and selection efficiency using part-records for production traits in strawberries. Theor. Appl. Genet. 78:560-566.

Shaw, D.V. 1989c. Genetic parameters estimated for an advanced-cycle strawberry breeding population at two locations. J. Amer. Soc. Hort. Sci. 114:823-827.

Shaw, D.V. 1992. Genetic correlations between vegetative growth traits and productivity at different within-season intervals for strawberries (Fragaria $\times$ ananassa). Theor. Appl. Genet. 85:1001-1009.

Van Vleck, D. 1983. Notes on the theory and application of selection principles for the genetic improvement of animals. Chapter VII. Cornell Univ. Press, Ithaca, N.Y.

Voth, V. and R.S. Bringhurst. 1970. Influence of nursery harvest date, cold storage, and planting date on performance of winter planted California strawberries. J. Amer. Soc. Hort. Sci. 95:496-500.

Voth, V. and R.S. Bringhurst. 1990. Culture and physiological manipulation of California strawberries. HortScience 25:889-892.

Walsh, D.B., F.G. Zalom, N.C. Welch, C. Pickel, and D.V. Shaw. 1997. Pre-transplant cold storage of strawberries: Effects on plant vigor, yield, and spider mite (Acari: Tetranychidae) abundance. J. Econ Entomol. 90:818-823. 